\title{
Design Course Teaching Practice Returning to Architecture Origin Kindergarten Curriculum Modular Construction
}

\author{
Ting Du \\ Binzhou University, Binzhou, Shandong, 256600
}

\begin{abstract}
Architectural design teaching must be based on the basic problems of architecture, strengthen the students' understanding and cognition of the origin of architecture, grasp the ability of grasping the essence and solving the problems in the constantly changing requirements of development. Based on the kindergarten curriculum design and teaching practice, this article explores the core elements of architectural design through the interrelationship between the use of object scale and cognition of behavior, as well as the construction of building space and scene construction, to rational judgment, and gradually understand and master the basic methods of architectural design.
\end{abstract}

Keywords: Scale experiment; Behavior cognition; Spatial construction; Scene presentation

DOI: 10.36012 /fhe.v1i2.1437

\section{Basic problem}

I $\mathrm{n}$ the past two years, the domestic construction market has undergone great changes, both as an inevitable trend of domestic economic development, but also experienced the rapid development of nearly 10 years of construction industry must pass. In the face of the new changes in the rapid social development, architectural design teaching should pay more attention to cultivating students' cognition and understanding of the essence of architecture, grasping the core elements of architectural design and learning to solve the problems.

What are the basic problems of architectural design? There are different interpretations and different emphases at different levels. From the aspects of "application, safety, economy and aesthetics" to "form, space, context and green", we are discussing the essential connotation of architecture and what is the basic problem to be solved in architectural design.

Architectural creation is a comprehensive and seemingly inaccessible process of rational control. However, for students of different stages, architectural design teaching must have clear and clear-cut curriculum guidelines so that students can gradually approach and understand the essence of architecture and grasp the core issues in constant training.

Kindergarten curriculum design is the first complete architectural design course for undergraduates after completing the basic learning stage of architectural design. Before this course, there was a design contact based on the self-experience of students to construct and organize a single building space. On this basis, the kindergarten curriculum design was expanded to deeply train students' ability to organize repetitive space.

Different from the design problems of repetitive spaces such as offices and rented dwellings, the design of kindergartens needs to be aimed at a special client young children. Kindergarten Curriculum Design Students are trained to understand the dimensions, behaviors and building styles of special users and to design buildings and spaces that are suitable for specific users. At the beginning of entering professional learning process, we should strengthen the use of the crowd, which is the most essential element of architecture in the architectural design.

On the other hand, the organization and construction of architectural space, though comprehensive and complicated, can also be divided and disassembled. In kindergarten curriculum design and teaching, different modules are specifically set from easy to difficult and from point to the surface, so that students can clear the concept of master space design and scene construction of the basic methods.

\section{Set up the course module}

Kindergarten curriculum design takes user awareness, situational imagination, spatial organization, skin structure, the scene presented five modules as the main line. On the basis of this, the course training is divided into seven sections: the observation of child scale and behavior; the generation of design theme; the analysis of scene environment; the cognition of activity unit; the combination of unit space; the design of space detail scene; Integration and expression. 


\subsection{Childhood dimensions and behavior cognitive module}

As a designer, it's hard to make a good design without the experience of using, not every type of building can let the designer have personal experience. How to design a building type that you can not experience is a problem that every designer's career will encounter.

Kindergarten curriculum design is such a building type. We have all experienced early childhood, but unfortunately it is too far away and almost unrecognizable. This requires students to regain their awareness of young children and look at a building from a young child's perspective and must also meet the needs of young children and adults. Only the setting of such topics will enable students to fully understand the role of clients in the building.

Therefore, the course is set up in two aspects: child-scale experiments; children's behavioral research.

\subsection{1 infant scale experiment}

Scale is a seemingly concrete, but the problem is actually very abstract. The scale is never absolute, but relative. The mastery of scales requires careful attention and reflection over time and again requires experience and experimentation.

Scale is the decisive element of space, so it is the difficulty and emphasis of our teaching practice. How to understand and present the scale is a difficult problem for mature architects, not to mention a beginner design student. Therefore, it is necessary for the teacher to guide the students to observe and understand the perspective of taking the concept of scale, and then guide students through analysis and analysis to understand and understand the scale and the relationship between architectural space, building components, for which we have taken a preschool-scale reading.

Based on the standard reading, students need to deeply understand and analyze the scale relations in space. Through the illustrated achievements, students can express their own analysis and cognition of children scales, spatial scales and component scales, and finally guide the design of curriculum. Although, students in lower grades may not be able to understand the scale of such a thorough and in-depth abstract issues. However, in the practice of teaching, emphasis is placed on the basic problem of scale, and a seed is planted. Irrigation and cultivation in the future will surely take root.

\subsection{2 children behavior research cognition}

Behavioral research requires students to engage with one or more childrens throughout the day to collect video clips of their childrens activities related to the internet and to display their analysis and understanding of children's activities through a short video.

These two perceptual exercises will guide students in the development of kindergarten curriculum design topics in the final presentation of different abstract scenes, and then lay the different colors for the entire design tone. This process takes the basic problem of the user as the research object and guides the students to pay attention to and understand. The service object is an important source of inspiration for us. Different perspectives lead to different conclusions and find the development of individuality in common satisfaction.(Figure 1: Environmental and behavior series research assignment)

\subsection{Scenarios imagination module}

Through the cognition of scale and behavior, the students are guided to recall the childhood life and observe the behavior characteristics of the children around them. The students' observation, perception and imagination are stimulated, and the spatial scenes are abstractly expressed in pictorial language. This phase trains students' descriptions of events, whether they abstract the presentation of the scene and how the architectural space is shaped.

\subsection{Game box-space organization module}

Based on the training of the first two modules, the conceptual elements of abstraction are transformed into formalized architectural design, so as to clarify the starting point of the design. Through the application of awareness of children behavioral standards, students should design a small-scale children interaction space "game box" before designing.

The "Game Box" needs to reflect the following spatial characteristics: Designing space, dimensions and game modes based on the characteristics of children and behavioral activities. Interface is open, according to their own design to determine the way to enter.

\subsection{Skin construction module}

In our past teaching, especially in lower grades, architectural design courses were completely separated from other theoretical courses, such as architecture, building materials, and building structures. This presents a theoretical lesson for students to take the exam. In turn, the need to address issues related to architec- 
tural design courses, but students can not understand the nature, just doing pure form of facade and skin. How to achieve the mastery of these courses is the need to think and solve the difficulties. Of course, such a large and complex system construction is not a design course can be solved, nor is it a semester to solve, but requires continuous learning, and even throughout his career.

Our design course did not evade this problem, try to combine the theory of architecture into the actual architectural design, combined with the building construction course and design course modules students started over the same period. Of course, because it is a lower grade student, the choice of difficulty is relatively simple, and more is to enable students to understand and approach the essence of building construction.

Construction is not easy for junior students and even current professional architects. Kindergarten curriculum design mainly focuses on the three parts of the wall, the wall window node and the wall grounding node so that students can clearly recognize that the building facade, shape design and building envelope of the close relationship.

\subsection{Scene rendering module}

Through a series of design training of the first few modules, students can change their thinking perspectives, view the building space from the perspective of young children, and adapt to the strategy of creating space under the cognitive behavior of young children. From the concept of space design, to extract the refined space order; from the "game box" space device design, the students can use a clear scale. From the diversity of cell space design, to explore the refined space; from the combination of repetitive patterns, students will integrate the space, and then complete the design. In the end, students were able to create a holis-
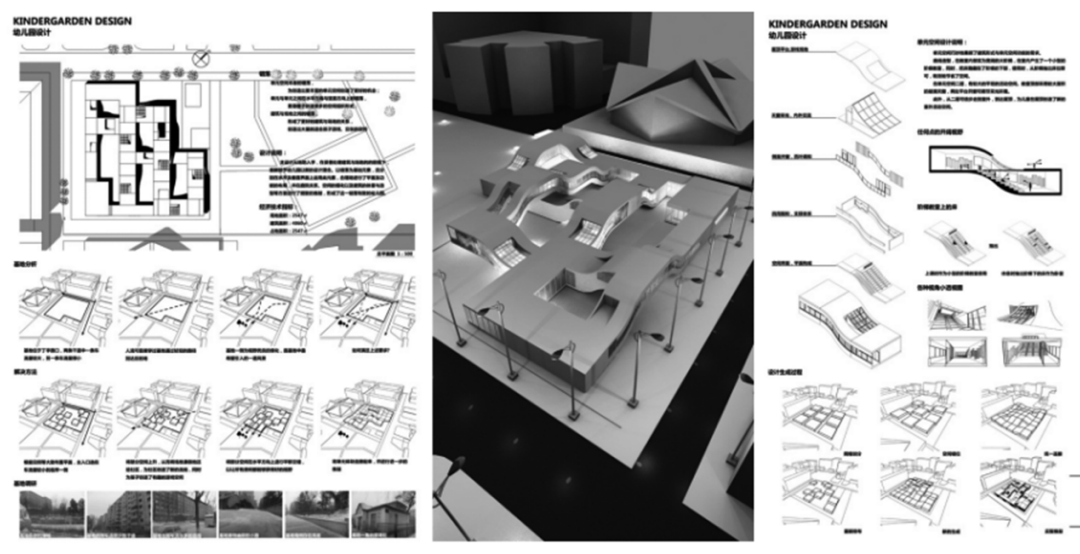

tic spatial context and design space for children to meet their child's standards and behavior patterns.(Figure 2:Kindergarten design homework results)

\section{Summary and reflection}

As the most important vocational training in architecture majors, curriculum design, it must be guided by its own problems, from beginning to end, from easy to difficult. Curriculum design should step by step guide students close to the nature of the building to adapt to the development and needs of society.

Qualified designers are caring people in life, experience unknown, observe the surrounding and learning technology, in order to be closer to the nature of the building, creating social significance and value of existence.

In the teaching practice of kindergarten curriculum design, we will continue to explore how to realize the standard cognition and understanding in the design, and reflect the changes in the spatial form of the building brought by the change of scale. Furthermore, the possibility of establishing a homework evaluation system based on the common design of design courses and technical theory courses is studied. At the same time, the principle of sharing homework and examination results among courses is studied. The integration and promotion of modular courses are more fully promoted and the students' effective learning, to stimulate students to think more about the fundamental problems of architecture and exploration.

\section{References}

[1] Wu Liangyong. Generalized Architecture. Beijing: Tsinghua University Press, 1989.

[2] Deng Qingtan. Nursery Kindergarten building design said. Jinan: Shandong Science and Technology Press, 2006.

[3] Cai Chunmei. Childhood behavior observation and record. Shanghai: East China Normal University Press, 2013. 